\title{
Haemagglutinating anti-actin antibodies in acute and chronic liver disease
}

\author{
A N HAMLYN* AND P A BERG \\ From the Division of Internal Medicine II, University Medical Clinic, Tübingen, Federal Republic \\ of Germany
}

SUMMARY Anti-actin antibody was measured by the passive haemagglutination test in the serum of 118 patients with various forms of chronic cholestatic and non-cholestatic liver disease, and of 23 patients with acute hepatitis B or non-A, non-B. Tanned sheep erythrocytes and electrophoretically pure actin prepared from rabbit skeletal muscle were employed; absorption tests confirmed the specificity of positive reactions, defined from healthy controls as a titre of greater than $1 / 80$. The presence of anti-actin activity in chronic liver disease corresponded generally to the immunofluorescent demonstration of smooth muscle antibody $(\mathrm{P}<0.01)$. However, in acute hepatitis, with one exception (later progressing to subacute disease) raised anti-actin titres were not found. Thus, the weak smooth muscle antibody occasionally demonstrable in this condition may be neither IgM in class, nor directed against actin. Anti-actin antibody was present in significantly high titre in $54 \%$ of 37 active chronic hepatitis patients and $79 \%$ of 24 'mixed-form' cholestatic active chronic hepatitis, as compared with only $21 \%$ of 29 primary biliary cirrhosis patients, and $11 \%$ of alcoholic liver disease. Anti-actin antibody is therefore associated with chronic autoimmune parenchymal liver damage and its appearance may mark the transition from acute hepatitis. No raised anti-actin titres were seen in 10 primary biliary cirrhosis patients positive for mitochondrial antibody by indirect immunofluorescence, but negative by the complement fixation test. This result suggests that the cytoplasmic fluorescence observed is due to low titre mitochondrial antibody rather than cytoplasmic actin and that these patients do not represent a different disease entity. The generation of anti-actin antibody in chronic parenchymal liver disease, perhaps due to unmasking or schlepping of intracellular or SIg/HLA-associated actin, may characterise autoimmune events at hepatocyte level, point to prognosis, and aid in the differential diagnosis of individual patients.

Smooth muscle antibodies (SMA) occur in patients with acute and chronic liver disease. ${ }^{12}$ The identity of the antigen involved was at first uncertain, but absorption experiments, ${ }^{34}$ immunodiffusion studies, ${ }^{4}$ and observed localisation of fluorescent conjugate to the actin-rich I bands of striated muscle ${ }^{5}$ suggest that, in active chronic hepatitis, SMA is directed against actin. Because of the potential diagnostic and prognostic importance of SMA we have investigated the quantitation of anti-actin antibidies in patients with various forms of liver disease, using actin-sensitised tanned sheep erythrocytes in the passive haemagglutination test.

*Address for correspondence: Dr A N Hamlyn, Department of Medicine, Wordsley Hospital, Stourbridge, West Midlands, D78 5QX, England.

Received for publication 6 November 1979

\section{Methods}

\section{PATIENTS}

Serum was obtained from patients with acute or chronic liver disease diagnosed on appropriate clinical and laboratory criteria. The categories studied included primary biliary cirrhosis (29 patients), active chronic hepatitis (total 37, of whom nine were positive for $\mathrm{HBsAg}$ and nine positive for antinuclear factor), alcoholic liver disease (18, of whom 16 had cirrhosis and two alcoholic hepatitis) and acute hepatitis B (nine). Also included were 14 patients with hepatitis non-A, non-B, defined as acute hepatitis occurring sporadically or after blood transfusion, with negative radioimmunoassay tests for $\mathrm{HBsAg}, \mathrm{HBcAg}, \mathrm{HBsAb}$, and IgM anti-HA, together with negative serological tests for cyto- 
megalovirus, infectious mononucleosis, or other hepatotrophic viruses. Twenty normal subjects (healthy laboratory personnel) were used as controls.

Also investigated were 24 patients with 'mixed form' cholestatic active chronic hepatitis. This is a relatively new diagnostic entity characterised by clinical features largely indistinguishable from those of primary biliary cirrhosis and liver histology of chronic aggressive hepatitis with or without cirrhosis, usually with late-stage periportal inflammation and atypical bile duct proliferation. ${ }^{6}$ A notable feature of these patients is the presence of antibiodies to a mitochondrial fraction distinct from that of primary biliary cirrhosis, ${ }^{7-9}$ and the frequent occurrence of SMA. Additionally studied were 10 patients with apparently classical primary biliary cirrhosis, in whom the mitochondrial antibody was positive by immunofluorescence but negative by complement fixation, raising the possibility of another, nonmitochondrial, cytoplasmic target antigen.

\section{TECHNIQUES}

All chemical reagents were Merck analytical grade unless otherwise stated; protein determinations employed a dye-binding method. ${ }^{10}$

\section{Preparation of actin}

Myosin-free acetone powder was prepared from rabbit skeletal muscle ${ }^{11}$ and actin extracted with dilute buffer in the cold.12 The purity of the actin obtained after successive repolymerisation stages was ascertained by means of disc electrophoresis in a slab consisting of $1 \%$ sodium dodecyl sulphate in $4 \%$ polyacrylamide (stacking gel) and in $8 \%$ polyacrylamide (separation gel). The molecular weight standards that were used were bovine serum albumin (Behring), bovine pancreatic trypsin (Merck), and cytochrome C (Fluka); all samples were pre-treated for five minutes at $100^{\circ} \mathrm{C}$ with sodium dodecyl sulphate and 2-mercaptoethanol, in order to reduce proteins to sub-units..$^{13}$ After the run the protein bands were fixed overnight in $50 \%$ trichloracetic acid (TCA), stained in $0.1 \%$ Coomassie Brilliant Blue G250 in 50\% TCA, destained in 7\% acetic acid, and photographed for subsequent microdensitometric scanning. Electrophoretically pure actin was stored at $-20^{\circ}$ in $50 \mathrm{mM} \mathrm{KCl}$ at a concentration of $1-2 \mathrm{mg} / \mathrm{ml}$. The effect of denaturing the antigen upon test performance was also investigated by treatment of the actin with $6 \mathrm{M}$ urea, ${ }^{14}$ lyophilisation, and repeated freeze-thawing.

Preparation of sensitised erythrocytes

A 4\% thrice-washed suspension of sheep erythrocytes (Behring) in $\mathbf{0 . 2 0}$ phosphate-buffered saline, pH 7.6 (PBS) was incubated with tannic acid in a final concentration of $1: 20000$ for 30 minutes at $37^{\circ}$. The tanned cells were washed once, the total volume divided and one-half incubated with actin at a final concentration of $0.1 \mathrm{mg} / \mathrm{ml}$ for 30 minutes at $\mathrm{pH} 7.6$ and room temperature, the other half being left uncoated. The two batches of cells were then washed three times in PBS containing $0.2 \%$ horse serum (Difco), being resuspended in PBS with $1 \%$ horse serum, at the working concentration of $2 \%$. The horse serum was added at this concentration, as preliminary work indicated that actin was an agglutinin, and careful stabilisation of the final preparation was important. Centrifugation after the tanning step was always limited to $100 \mathrm{~g}$ for 20 minutes to avoid spontaneous agglutination; cell concentrations were adjusted by spectrophotometric estimation of the haemoglobin released by laking.

\section{Haemagglutinating anti-actin antibody titration}

Sera stored at $-20^{\circ} \mathrm{C}$ were studied, samples were decomplemented by heating at $56^{\circ} \mathrm{C}$ for 30 minutes. The serum was diluted 1:5 with PBS and heterophile and antialbumin antibodies absorbed out by incubation with a $4 \%$ suspension of stabilised erythrocytes for one hour at room temperature. After centrifugation at $1000 \mathrm{~g}$ for five minutes doubling dilutions of $25 \mu \mathrm{l}$ samples were carried out in PBS$1 \%$ horse serum, using V-cup Cooke Microtiter trays. A $2 \%$ suspension of sensitised cells $(25 \mu \mathrm{l})$ was then added to each cup, and the tray agitated briefly. After incubation at room temperature for two hours the preparations were read, using an inverted magnifying mirror. The endpoint of agglutination was taken as a button of erythrocytes in the bottom of the cup, surrounded by a ring of agglutinated cells. The upper range of normal was established in 20 healthy subjects as $1 / 80$.

\section{Validation}

Different batches of sensitised cells were prepared and the repeatability of the method assessed by duplicate determinations on coded sera. As passive haemagglutination may be effected by both IgG and IgM the effect of IgM antibody dissociation was studied by initially diluting sera in PBS containing 0.1M 2-mercaptoethanol. ${ }^{15}$ Specificity of the test system was investigated by incubating high titre marker sera with actin $(1 \mathrm{mg} / \mathrm{ml}$ of serum) overnight at $4^{\circ} \mathrm{C}$, centrifuging at $12000 \mathrm{~g}$ for one hour and analysing the supernatant for anti-actin haemagglutinating activity.

\section{Immunofluorescence studies}

Sera diluted 1:10 in PBS were incubated for 30 minutes with fresh cryostat sections of rat liver, kidney, and stomach at room temperature. The 
presence of smooth muscle antibody was demonstrated then with the aid of fluorescein-conjugated goat antihuman globulin (Hyland polyspecific conjugate, cat. no. HDO72-202), at a working dilution of 1:10. Results were read in a Leitz Orthoplan microscope, using a KP500 transmission filter and an S525 barrier filter.

\section{Other investigations}

Hepatitis B antibodies and antigens (HBsAg, $\mathrm{HBsAb}, \mathrm{HBcAg}$, and e antigen) and IgM antibodies to hepatitis $\mathrm{A}$ antigen were tested for by standard radioimmunoassay procedures. Hepatitis ' $\mathrm{C}$ ' antigen was also looked for in non-A, non-B hepatitis sera using late-phase sera as the presumptive antisera in the immunodiffusion system suggested by Schirachi et al. ${ }^{16}$ For confirmation of the diagnosis of primary biliary cirrhosis antibodies against mitochondrial antigen fractions were tested for by complement fixation. ${ }^{17}$

\section{Results}

\section{PURITY OF ANTIGEN}

A single peak on SDS-polyacrylamide gel electrophoresis was obtained at actin concentrations of 10-20 $\mu \mathrm{g}$. At higher concentrations, up to $40 \mu \mathrm{g}$ per sample, one or two faint bands were seen to run ahead of the main one (Fig. 1). Microdensitometric integration of the area under the peaks confirmed the high purity of the preparation. The relative mobility of the main peak was equivalent to a molecular weight of 42000 , corresponding to that obtained by amino-acid sequencing. ${ }^{18}$ In addition, polymerisation of actin monomer in $50 \mathrm{mM} \mathrm{KCl}$ resulted in a very viscous solution, the polymeric fibrous form or F-actin.

\section{CHARACTERISTICS OF}

\section{ACTIN-SENSITISED CELLS}

Freshly prepared actin was maximally antigenic: both lyophilisation and treatment with $6 \mathrm{M}$ urea abolished sensitising ability. Storage of $1-2 \mathrm{mg} / \mathrm{ml}$ actin in $50 \mathrm{mM} \mathrm{KCl}$ at $-20^{\circ} \mathrm{C}$ for 20 weeks did not alter antigenicity, although three cycles of freezing and thawing from $-150^{\circ} \mathrm{C}$ (frozen $\mathrm{CO}_{2}$ snow in acetone) greatly diminished it. Absorption studies using different batches of actin with high titre sera confirmed the specificity of positive reactions (Fig. 2). Retesting studies also confirmed the repeatability of positive reactions: only three of 36 retests gave endpoints differing by two or more titration steps and the correlation coefficient between each set of titres was 0.99. Even after preabsorption with uncoated, stabilised cells a few sera gave haemagglutination titres of over $1 / 80$, indicating high-titre

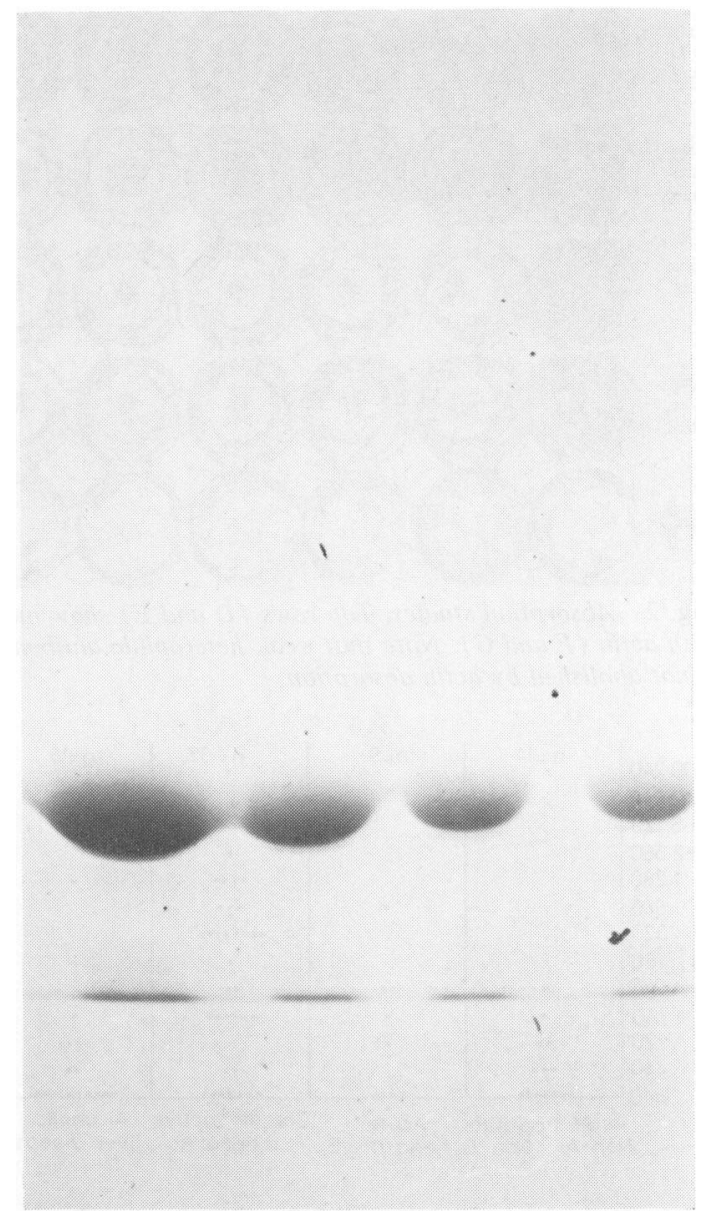

Fig. $1 S D S$-polyacrylamide gel electrophoresis of actin 40,30,20, and $10 \mu \mathrm{g}$ at $6 \mathrm{~V} / \mathrm{cm}$ for 180 minutes. $A$ single band is apparent at all but the highest concentration.

heterophile or anti-albumin antibody; these cases have not been included in the present study.

\section{Results in disease}

\section{HAEMAGGLUTINATING ANTI-ACTIN} ANTIBODY IN CHRONIC LIVER DISEASE

Within the active chronic hepatitis group there was no statistical difference in geometric mean titre difference between those without and those with ('lupoid') antinuclear factor, or those with evidence of hepatitis B infection. Of this entire group 20/37 $(54 \%)$ had titres above the normal range, compared with only $2 / 18(11 \%)$ of alcoholic liver disease patients $(\mathrm{P}<0.01$, Fig. 3). In 'mixed form' cholestatic active chronic hepatitis 19/24 (79\%) had high anti- 




Fig. 2 Absorption studies. Top rows ( $D$ and $E$ ) show moderate and high anti-actin titres abolished by absorption with actin $(F$ and $G)$. Note that weak heterophile antibody activity (right-hand well, row D) against uncoated cells is not abolished by actin absorption.

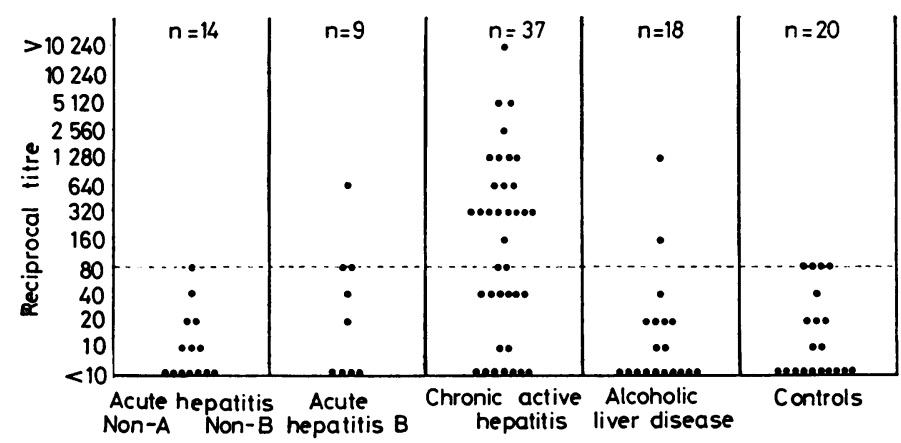

Fig. 3 Haemagglutinating anti-actin titres in acute and chronic liver disease. Dotted lines indicate upper limit of normal control titres. Significantly higher titres are seen in active chronic hepatitis. Lower titres are seen in alcoholic liver disease and acute hepatitis (titres shown are highest determined in first eight weeks of illness).

actin titres, compared with $6 / 29(21 \%)$ of primary biliary cirrhosis $(P<0.002$, Fig. 4). Raised anti-actin titres were not seen in patients with primary biliary cirrhosis positive for mitochondrial antibody by immunofluorescence, but negative by complement fixation.

COMPARISON OF ANTI-ACTIN ANTIBODY WITH IMMUNOFLUORESCENCE TESTING FOR SMA

This was studied in 83 patients with chronic liver disease. Of those with positive SMA $26 / 40(65 \%)$ had raised anti-actin titres, compared with $6 / 43$ $(14 \%)$ in those negative for SMA $\left(\chi^{2}=23 \cdot 2\right.$, $P<0.01)$. Of all anti-actin titres of $1 / 80$ or below, only $28 \%$ had smooth muscle antibody (Fig. 5).

\section{EFFECT OF 2-MERCAPTOETHANOL}

After treatment of 24 sera with raised anti-actin titres 23 fell into the normal range (Fig. 6). The exception occurred in a patient with $\mathrm{HBsAg}$ positive active chronic hepatitis.

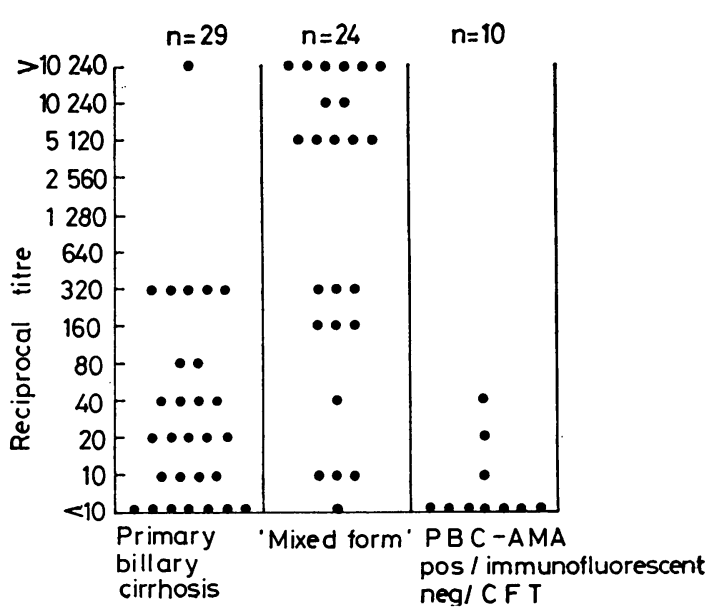

Fig. 4 Haemagglutinating anti-actin titres in chronic cholestatic liver disease. Raised anti-actin titres are significantly more frequent in 'mixed-form' disease as compared with primary biliary cirrhosis (PBC) whether positive for mitochondrial antibody by CFT or not. 


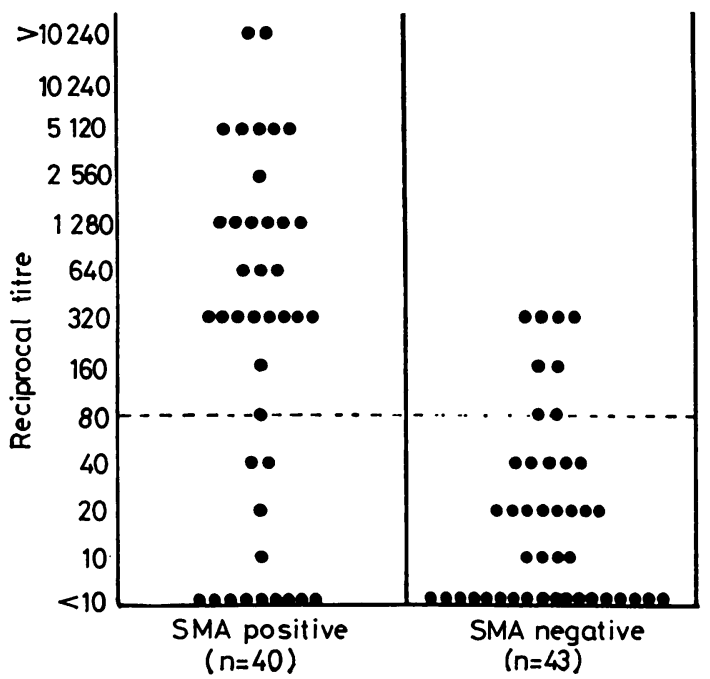

Fig. 5 Chronic liver disease: relationship between anti-actin activity and SMA.

\section{RELATIONSHIP OF ANTI-ACTIN TITRE TO} DISEASE SEVERITY

No consistent relationship, as judged by transaminase levels and histological evidence of active inflammatory change in the liver, was observed between severity and anti-actin titres. On the other hand, anti-actin titres tended to be higher in chronic aggressive non-cholestatic liver disease. The single case of alcoholic liver disease with an anti-actin titre of $1 / 1280$ in fact had alcoholic hepatitis with severe inflammatory reaction on biopsy.

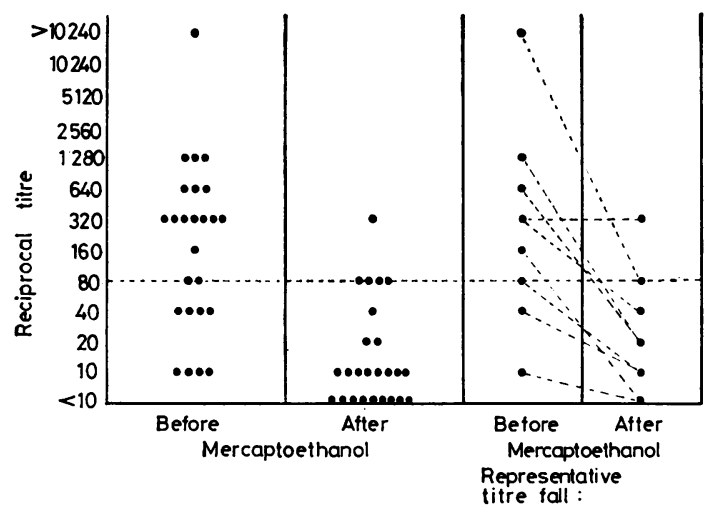

Fig. 6 Effect of 2-mercaptoethanol: left-hand columns show aggregated results for 23 patients with chronic liver disease, right-hand column shows some individual results. There are significant titre falls, demonstrating that mainly IgM is being detected.
ANTI-ACTIN TITRES IN ACUTE HEPATITIS

Of the nine patients with acute hepatitis B only one at any stage exhibited a high anti-actin titre of $1 / 640$. This was a patient with an unduly protracted clinical course who, six months later, still had liver biopsy evidence of subacute hepatitis. In the 14 non-A, non-B hepatitis cases (all negative for the hepatitis ' $\mathrm{C}$ ' antigen by radial immunodiffusion against convalescent sera) no case showed a raised titre, all being negative for SMA (Fig. 3). Three of this group ultimately experienced clinical and transaminase relapse.

\section{Discussion}

Positively charged side-groups, which would be few at neutral $\mathrm{pH}$, are necessary for adequate attachment of coating antigens to erythrocytes. ${ }^{19}$ Actin monomer has a large net negative charge, the isoelectric point being about $4 \cdot 8,{ }^{18}$ so that it is surprising that erythrocytes prepared under these conditions should be adequately sensitised. However, not only is incubation carried out at osmolarities at which actin polymer (F-actin) forms, but also tannin treatment reduces erythrocyte (zeta) potential. Possibly also charged groups are unmasked by mild denaturative changes during actin preparation and this accounts as well for the ability of actin to destabilise tanned erythrocyte suspensions. On the other hand, preservation of the tertiary structure of F-actin is necessary for antigenicity, as negative results are obtained with marker serum when actin is strongly denatured by urea or lyophilisation, and enzyme-linked immunosorbent analysis confirms the lack of immunogenicity of monomeric (G) actin. ${ }^{20}$ The relationship of anti-actin antibody to SMA was demonstrated in active chronic hepatitis by Gabbiani et al. ${ }^{3}$ and Lidman et al., ${ }^{4}$ the latter succeeding in absorbing SMA with rabbit skeletal muscle actin. These sera were, however, 'broad-reacting'- that is, reacted not only with smooth muscle but also with non-muscular structures such as renal glomeruli and epithelial cell brush borders. Many positive sera are more restricted in spectrum of specificity, because of either titre effect or involvement of other muscle antigens. Thus one study ${ }^{21}$ found that the full range of smooth muscle, glomerular and epithelial cell immunofluorescence could be reproduced using antibody raised to human uterine actomyosin, myosin, heavy meromyosin, light meromyosin, and tropomyosin. In particular, actin-absorbable antibodies also give rise to fluorescence localised to renal glomeruli and bile-duct epithelial cells, an effect also obtained with anti-heavy meromyosin conjugate. The abolition of SMA activity by absorption with janin, a new smooth muscle antigen, has also been described. ${ }^{22}$ 
This was found in $17 \%$ of positive sera, confirming the importance of non-actin antigens in SMA specificity. Nevertheless, actin antibodies are probably present in the majority of SMA-positive active chronic hepatitis patients, and, in view of their importance, it seems necessary to develop quantitative assays which obviate the necessity for complicated absorption procedures.

Passive haemagglutination was chosen as an investigative tool because of its sensitivity and convenience. It is not, however, an unselective test for all classes of antibody. IgM has been shown to be about 750 times more efficient than IgG at agglutinating sensitised red cells ${ }^{23}$ and the IgM class of the antibodies found by passive haemagglutination is confirmed by the fall in titres which we observed after mercaptoethanol treatment. The failure of immunofluorescence results to correspond more closely with haemagglutination titres may also be explained by the IgM bias of the test, as some polyspecific conjugates may reveal IgG antibodies more efficiently. The observed disparities cannot be explained by interspecies differences in the composition of the actin involved (rat for immunofluorescence, rabbit for passive haemagglutination); and, although minor substitutions of surface amino acids mark the main differences between muscle and cytoplasmic actin in the same species, such substitutions would be unlikely to modify immunogenicity. ${ }^{24}$ Thus, the majority of instances of anti-actin antibody in chronic liver disease seem to be associated with SMA. The fact that we found mostly low anti-actin titres in acute hepatitis implies that the IgM SMA found in these patients ${ }^{25}$ is not of anti-actin specificity and that, if such antibodies appear, they may be associated with chronicity.

Smooth muscle antibodies are said to occur in primary biliary cirrhosis in $30-50 \%$ of patients. ${ }^{26-28}$ However, one survey using matched controls found an incidence little higher than normal. ${ }^{29}$ The occurrence of haemagglutinating antibody to actin in these patients suggests that, when it occurs, it is of antiactin specificity. We were unable to differentiate primary biliary cirrhosis from 'mixed form' disease solely on the basis of this test. The reasons for the appearance of anti-actin antibody in chronic liver disease have been clarified by recent work. Microfilaments containing actin are present along the periphery of hepatocytes ${ }^{30}$ and it has now been shown that cellular actin is physically associated with surface immunoglobulin and a surface receptor, the $\mathrm{H}-2$ histocompatibility antigen complex. ${ }^{31}{ }^{32}$ The generation of SMA in some virus infections ${ }^{33} 34$ may be due, therefore, to a 'schlepper' effect of exogenous antigen upon the actin-HLA antigen apparatus or formation of circulating virus-SIg-actin complexes.
The predominance of anti-actin antibodies in chronic parenchymal liver disease, whether HBsAg positive or negative, emphasises the probable importance of surface membrane events in active chronic hepatitis and further differentiates this group of diseases from primary biliary cirrhosis. The use of actin-antibody tests in hepatology may thus not only help to elucidate the mechanisms of chronicity, but also materially aid prognosis and diagnosis.

ANH was supported by a European Travelling Scholarship from the Wellcome Trust. We are grateful to Miss Kristin May for drawing the figures and for other invaluable technical help.

\section{References}

'Johnson GD, Holborow EJ, Glynn LE. Antibody to smooth muscle in patients with liver disease. Lancet 1965; 2: 878-9.

${ }^{2}$ Whittingham S, MacKay IR, Irwin J. Autoimmune hepatitis. Immunofluorescence reactions with cytoplasm of smooth muscle and renal glomerular cells.

Lancet 1966; 1 : 1333-5.

${ }^{3}$ Gabbiani G, Ryan GB, Lamelin JP, et al. Human smooth muscle antibody. Its identification as antiactin antibody and a study of its binding to nonmuscular cells Am J Pathol 1973; 72: 473-88.

${ }^{4}$ Lidman K, Biberfeld G, Fagraeus A, et al. Anti-actin specificity of human smooth muscle antibodies in chronic active hepatitis. Clin Exp Immunol 1976; 246: 266-72.

${ }^{5}$ Chaponnier G, Kohler L, Gabbiani G. Fixation of human anti-actin autoantibodies on skeletal muscle fibres. Clin Exp Immunol 1971; 27: 278-84.

${ }^{6}$ Klöppel G, Seifert G, Lindner H, et al. Histopathological features in mixed types of chronic aggressive hepatitis and primary biliary cirrhosis. Virchows Arch (Path Anat) 1977; 373: 143-60.

${ }^{7}$ Berg PA, Binder $\mathrm{T}$, Lindner $\mathrm{H}$, et al. Heterogenität mitochondrialer Autoantikörper. Dtsch Med Wochenschr 1975; 100: 1123-7.

${ }^{8}$ Berg PA, Binder T, Breitsöhl--Mörck C, et al. Heterogenität mitochondrialer Antikörper (AMA): Zur Bedeutung des Nachweises von AMA Antikörpern bei der cholostatisch verlaufenden chronisch aggressiven Hepatitis. Verh Dtsch Ges Inn Med 1976; 82: 1833-6.

${ }^{9}$ Berg PA, Lindner H, Breitsöhl-Mörck C, Merk KH, Schlote W. Different specificities of antimitochondrial antibodies in sera from patients with PBC and chronic active hepatitis with cholestasis. (Abstract.) Digestion 1976; 14 : 457-8.

${ }^{10}$ Bradford MM. A rapid and sensitive method for the quantitation of microgram quantities of protein utilizing the principle of protein-dye binding. Anal Biochem 1976; 72: 248-54.

11yengar MR, Weber $\mathrm{HH}$. The relative affinities of nucleotides to G-actin and their effects. Biochem Biophys Acta 1964; 86: 543-53. 
${ }^{12}$ Spudich JA, Watt $\mathrm{S}$. The regulation of rabbit skeletal muscle contraction. I. Biochemical studies of the interaction of the tropomyosin-troponin complex with actin and the proteolytic fragments of myosin. $J$ Biol Chem 1971; 246: 4866-71.

${ }^{13}$ Laemmli K, Cleavage of structural proteins during the assembly of the heads of bacteriophage T4. Nature (Lond) 1970; 227: 680-5.

${ }^{14}$ George M, Vaughan JH, Observations on the nature of the antigen in tanned red cell haemagglutination. J Immunol 1962; 48: 191-8.

${ }^{15}$ Morris JE, Inman FP, Isolation of the monomeric subunit of immunoglobulin $\mathbf{M}$ with its interchain sulphide bonds intact. Biochemistry 1968; 7: 2851-7.

${ }^{16}$ Schirachi R, Shiraishi H, Tateda A. Kikuchi K, Ishida $\mathrm{N}$. Hepatitis ' $\mathrm{C}$ ' antigen in non- $\mathrm{A}$, non-B post-transfusion hepatitis. Lancet 1978: 2: 853-6.

${ }^{17}$ Walker JG, Donaich D, Roitt IM, Sherlock S. Serological tests in diagnosis of primary biliary cirrhosis. Lancet 1965; 1 : 827-31.

${ }^{18}$ Maurer PH, Gerulat BF, Pinchuck P. Antigenicity of polypeptides (poly $\alpha$-amino acids). V. Studies in rabbits. J Immunol 1963; 90: 381-7.

${ }^{19}$ Collins JH, Elzinga M. The primary structure of actin from rabbit skeletal muscle. Completion and analysis of the amino-acid sequence. J Biol Chem 1975; 250: 5915-20.

${ }^{20}$ Andersen P, Small JV, Andersen HK, Sobieszek A. Reactivity of smooth muscle antibodies with F- and G-actin. Immunology 1979; 37: 705-9.

${ }^{21}$ Trenchev P, Sneyd P, Holborow EJ. Immunofluorescent tracing of smooth muscle contractile protein antigens in tissues other than smooth muscle. Clin Exp Immunol 1974; 16: 125-36.

${ }^{22}$ Trenchev P. Antigenicity of janin, a new protein from smooth muscle. Clin Exp Immunol 1976; 26: 267-72.
${ }^{23}$ Greenbury CL, Moore DH, Nunn LAC. Reaction of 7S and 19S components of immune rabbit antisera with human group A and AB red cells. Immunology 1963; 6: 421-33.

${ }^{24}$ Vandekerckove J, Weber $\mathrm{K}$. The amino-acid sequence of Physarum actin. Nature (Lond) 1978; 276: 720-1.

${ }^{25}$ Farrow LJ, Holborow EJ, Johnson CO, et al. Autoantibodies and the hepatitis-associated antigen in acute infective hepatitis. $\mathrm{Br}$ Med J 1970; 2: 693-5.

${ }^{26}$ Doniach D, Roitt IM, Walker JG, Sherlock S. Tissue antibodies in primary biliary cirrhosis, active chronic (lupoid) hepatitis, cryptogenic cirrhosis and other liver diseases and their clinical implications. Clin Exp Immunol 1966; 1: 237-62.

${ }^{27}$ Doniach D, Walker G. Immunopathology of liver disease. Progr Liver Dis 1972; 4: 381-402.

${ }^{28}$ Hadziyannis S, Scheuer PJ, Feizi T, Naccarato R, Doniach D, Sherlock S. Immunological and histological studies in primary biliary cirrhosis. J Clin Pathol 1970; 23 : 95-8.

${ }^{29}$ Schaffner F. Primary biliary cirrhosis. Clin Gastroenterology 1975; 4: 351-66.

${ }^{30}$ French SW, Davies PL. Ultrastructural localization of actin-like filaments in rat hepatocytes. Gastroenterology 1975; 68: 765-74.

${ }^{31}$ Flanagan J, Koch GLE. Cross-linked surface Ig attaches to actin. Nature (Lond) 1978; 273: 278-81.

${ }^{32}$ Koch GLE, Smith MJ. An association between actin and the major histocompatibility antigen H-2. Nature (Lond) 1978; 273: 274-8.

${ }^{33}$ Andersen P, Andersen HK. Smooth muscle antibodies and other tissue antibodies in cytomegalovirus infection. Clin Exp Immunol 1975; 22: 22-9.

${ }^{34}$ Sutton RNP, Emond RTD, Thomas DB, Doniach D. The occurrence of antoantibodies in infectious mononucleosis. Clin Exp Immunol 1974; 17 : 427-36. 